\title{
Self-healing Passivation of Antimicrobial Iron oxide Nanoparticles for Epoxy Nanocomposite Coatings on Carbon Steel
}

\author{
Ayman M. Atta ${ }^{1,2, *}$, Ashraf M. El-Saeed ${ }^{1}$, H. I. Al-Shafey ${ }^{1}$ and Gamal A. El-Mahdy ${ }^{3}$ \\ ${ }^{1}$ Petroleum Application Department, Egyptian Petroleum Research Institute, Nasr City 11727, Cairo, \\ Egypt. \\ ${ }^{2}$ Chemistry department, college of science, King Saud University, Riyadh 11451, Saudi Arabia. \\ ${ }^{3}$ Chemistry Department, Faculty of Science, Helwan University, Helwan, Egypt. \\ *E-mail: aatta@ksu.edu.sa
}

doi: $10.20964 / 2016.07 .82$

Received: 14 April 2016 / Accepted: 19 May 2016 / Published: 4 June 2016

\begin{abstract}
Self-healing smart nanomaterials are fast responsive materials that can be used to repair organic coating defects. In this work, the ability of smart nanomaterials based on iron oxide nanoparticles capped with Myrrh to form protective films for epoxy nanocomposites defect in corrosive medium is investigated. The functionalization of iron oxide nanoparticles with Myrrh, their crystal shape and morphologies were confirmed by advanced analyses. The mechanical characteristics of iron oxide epoxy nanocomposites such as impact strength, bending and abrasion resistances and their adhesion performances with steel were measured using different iron oxide nanoparticles contents ranged from 0.1 to $10 \mathrm{Wt} \%$. The corrosion resistances of epoxy iron oxide nanocomposites were measured using salt spray resistance and electrochemical methods to investigate the barrier properties and self-healing performance of the epoxy coatings without and with the additions of iron oxide nanoparticles.
\end{abstract}

Keywords: Iron oxide; nanoparticles; epoxy; nanocomposites; coatings; corrosion.

\section{FULL TEXT}

(C) 2016 The Authors. Published by ESG (www.electrochemsci.org). This article is an open access article distributed under the terms and conditions of the Creative Commons Attribution license (http://creativecommons.org/licenses/by/4.0/). 